\title{
The novel angiogenic cytokine secretoneurin promotes angiogenesis, arteriogenesis and vasculogenesis in the mouse hind-limb ischemia model
}

Wilfried Schgoer ${ }^{1}$, Margot Egger ${ }^{1}$, Arno Beer ${ }^{1}$, Markus Theurl ${ }^{1}$, Johannes Jeschke ${ }^{2}$, Ivan Tancevski ${ }^{1}$, Philipp Eller ${ }^{1}$, Andreas Ritsch ${ }^{1}$, Hildegunde Piza-Katzer ${ }^{2}$, Josef R Patsch ${ }^{1}$, Peter Schratzberger ${ }^{1}$, Reiner Fischer-Colbrie ${ }^{3}$ and Rudolf Kirchmair*1

\author{
Address: ${ }^{1}$ Department of Internal Medicine, Medical University of Innsbruck, 6020 Innsbruck, Austria, ${ }^{2}$ Department of Plastic Surgery, Medical \\ University of Innsbruck, 6020 Innsbruck, Austria and ${ }^{3}$ Department of Pharmacology, Medical University of Innsbruck, 6020 Innsbruck, Austria \\ Email: Rudolf Kirchmair* - rudolf.kirchmair@i-med.ac.at \\ * Corresponding author
}

from 14th Scientific Symposium of the Austrian Pharmacological Society (APHAR)

Innsbruck, Austria. 21-22 November 2008

Published: 5 November 2008

BMC Pharmacology 2008, 8(Suppl I):A38 doi:I0.II86/I47I-22I0-8-SI-A38

This abstract is available from: http://www.biomedcentral.com/I47I-22I0/8/SI/A38

(c) 2008 Schgoer et al; licensee BioMed Central Ltd.

\section{Introduction}

Secretoneurin (SN) represents a sensory, inflammatory neuropeptide which was recently demonstrated to act as an angiogenic and vasculogenic cytokine in vitro and in vivo. The present study was conducted to test the hypothesis that SN may be implicated in reparative angiogenesis. Furthermore, we challenged the healing potential of SN applied as a newly generated $\mathrm{SN}$ gene therapy vector in the setting of limb ischemia.

\section{Methods and results}

We cloned the human SN coding sequence into the pAAV plasmid containing a cytomegalovirus enhancer/promoter sequence. To establish the bioactivity of the constructed SN plasmid (p-SN), we transfected p-SN into COS cells and verified protein expression by $\mathrm{SN}$-specific RIA. Bioactivity of recombinant SN was shown by proliferative and chemotactic activity on endothelial cells in vitro. Unilateral limb ischemia was induced in C57/bl6 mice by femoral artery resection. By real time PCR, western blotting, SN-specific RIA and immunhistochemistry, we documented that $\mathrm{SN}$ is up-regulated in ischemic muscles. We tested whether SN gene therapy may exert curative effects in this ischemia model. Injection of the SN plasmid into ischemic adductor muscles increased capillary ( 670 vs. $\left.350 / \mathrm{mm}^{2}, \mathrm{n}=12, \mathrm{p}=0.02\right)$ and arteriole ( 16 vs. $8 / \mathrm{mm}^{2}, \mathrm{n}=12, \mathrm{p}=0.04$ ) density, reduced endothelial cell apoptosis, and accelerated perfusion recovery as shown by laser Doppler perfusion imaging (LDPI; ratio ischemic/control leg after 28 days of ischemia: 1.1 vs. 0.7, $\mathrm{n}=12, \mathrm{p}<0.01$ ) in comparison to p-GFP (green fluorescent protein)-treated mice. Furthermore, SN gene therapy significantly reduced toe necrosis of ischemic limbs compared to control animals ( $26 \%$ vs. $50 \%, \mathrm{n}=12, \mathrm{p}<0.05)$. In bone marrow transplantation models, increased vascularity of ischemic hind-limbs after SN gene therapy was shown to be mediated, at least in part, by enhanced recruitment of bone marrow-derived endothelial progenitor cells.

\section{Conclusion}

These results suggest that the novel angiogenic cytokine secretoneurin is up-regulated by ischemia in skeletal muscle cells. Furthermore, results from gene therapy in this ischemia model suggest that secretoneurin represents a promising new substance for therapeutic angiogenesis. 